DOI: https://doi.org/10.24867/05BE00Knezevic

\title{
SIMULACIONI MODEL METODE ZA GENERISANJE ŠUMA DISKRETNOG U VREMENU I KONTINUALNOG PO VREDNOSTI
}

\section{SIMULATION MODEL OF CONTINUOS VALUE NOISE GENERATOR DISCRETE IN TIME}

\author{
Marko Knežević, Dragan Pejić, Fakultet tehničkih nauka, Novi Sad
}

\section{Oblast - ELEKTROTEHNIKA I RAČUNARSTVO}

Kratak sadržaj - U radu je prikazan simulacioni model nove metode za generisanje naponskog šuma uniformne raspodele vrednosti. Ovaj šum, diter, je ključni element u radu stohastičke analogno digitalne (AD) konverzije. Za razliku od uobičajenog načina generisanja primenom šift registra sa linearnom povratnom spregom (Linear Feedback Shift Register - LFSR) i digitalno analognog (DA)konvertora nova metoda je zasnovana na asinhronom odabiranju testerastog ili trougaonog napona. Kao osnovni dobitak predložene metode se navodi kontinualnost ditera po vrednosti, za razliku od prethodnog rě̌enja koje karakteriše diskretan diter. Primena kontinualnog ditera omogućava dalje povećanje efektivne rezolucije stohastičkog AD konvertora.

Ključne reči: $A D$ konvertor, diter u kontiualnom vremenu, generator šuma, programiranje, $c++$

Abstract - This paper presents simulation model of uniform noise generator of voltage signal. The noise, dither, is the main principle of stochastic AD conversion. Unlike the common way of generation, this metod uses Linear Feedback Shift Register - LFSR and it's based on an asinchrous sampling of triangle or sawtooth voltage signal. Main goal of the metod is time-contious jitter which has effect on further increase of effective resolution of stochastic AD converter.

Keywords: $A D$ conversion, time-contious jitter, noise generator, programming, $c++$

\section{UVOD}

Na Katedri za električna merenja Fakulteta tehničkih nauka u Novom Sadu se već 25 godina razvija stohastička AD konverzija [1]. Ova metoda je zasnovana na korišćenju fleš AD konvertora male rezolucije, najčešće rezo-lucije 2 bita. Mala rezolucija ugrađenog AD konvertora se kompenzuje dodavanjem šuma posebnih svojstava (diter) na ulazni signal, kao i usrednjavanjem velikog broja odbiraka dobijenih na visokoj učestanosti (engleski: oversampling). Diter treba da bude šum uniformne funkcije gustine raspodele opsega jednakog +/- polovini kvanta korišćenog fleš AD konvertora. Razvijena teorija [2] predviđa adaptivnost kao vrlo korisnu osobinu stohastičkog konvertora: za duže merenje se dobija manja greška.

\section{NAPOMENA:}

Ovaj rad proistekao je iz master rada čiji mentor je bio dr Dragan Pejić, vanr. prof.
Greška opada sa kvadratnim korenom iz dužine trajanje merenja. Za četiri puta duže merenje, dobija se duplo manja greška. Greška kojom se bavi teorija je isključivo slučajne prirode izazvana prisustvom šuma idealizovanih osobina. U praksi [3] se pokazuje kao ograničavajući faktor prisustvo sistematskih grešaka usled neidealnost ditera, ali i svih primenjenih komponenti.

$\mathrm{U}$ prethodnim godinama razvoja stohastičke metode su otklonjene mnoge sistematske greške [4]. U ovom trenutku se procenjuje da najveća preostala sistematska greška potiče od konačne rezolucije diterskog signala generisanog primenom DA konvertora.

Predložena je nova metoda [5] koja daje mogućnost generisanja ditera bez primene DA konvertora. Ovaj rad se bavi softverskim simulacionim modelom namenjenim za proveru predložene metode.

\section{PRIKAZ NOVE METODE}

Na slici 1. je prikazan testerasti napon $u(t)$, frekvencije $f=\frac{1}{T}$ i impulsi osam puta veće učestanosti $f_{s}=8 f$. Ako pretpostavimo da se odabiranje testerastog napona vrši na svaku uzlaznu ivici digitalnog signala, dobićemo 8 vrednosti koje su ekvidistantno raspoređene unutar opsega testerastog napona. Sa desne strane je prikazana diskretna funkcija gustine raspodele vrednosti odbiraka.

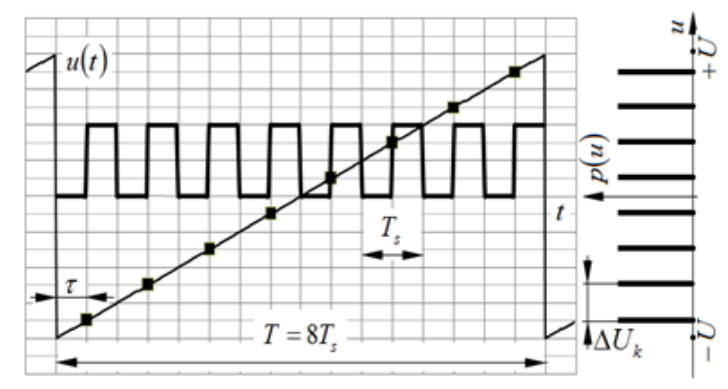

Slika 1. Celobrojni odnos učestanosti

Na slici 2. su prikazane dve periode testerastog napona i impulsi učestanosti $f_{s}=\left(8-\frac{1}{2}\right) f=7.5 f$. Sada će se, u dve susedne periode testerastog napona, desiti 15 ekvidistantno raspoređenih vrednosti odbiraka. $\mathrm{Na}$ ovaj način se može vršiti dalje uopštavanje, čiji rezultat je sve veći broj mogućih vrednosti odbiraka. Bitno je naglasiti da se pri ovome ne povećava učestanost odabiranja, što je jako važno u praktičnoj izvedbi. 


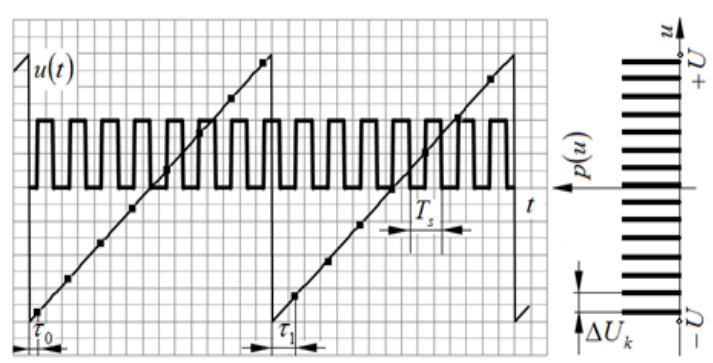

Slika 2. Necelobrojni odnos učestanosti

U Tabeli 1. je prikazan broj mogućih vrednosti odbiraka u zavisnosti od odnosa učestanosti odabiranja i učestanosti testerastog napona.

Tabela 1. Broj mogućih vrednosti

\begin{tabular}{|c|c|}
\hline Odnos učestanosti & Broj mogućih vrednosti \\
\hline$\frac{f_{s}}{f}$ & $N$ \\
\hline $2^{n} \pm \frac{1}{2}$ & $2^{\mathrm{n}+1} \pm 2^{0}$ \\
\hline $2^{n} \pm \frac{1}{2} \pm \frac{1}{4}$ & $2^{\mathrm{n}+2} \pm 2^{1} \pm 2^{0}$ \\
\hline $2^{n} \pm \frac{1}{2} \pm \frac{1}{4} \pm \frac{1}{8}$ & $2^{\mathrm{n}+3} \pm 2^{2} \pm 2^{1} \pm 2^{0}$ \\
\hline
\end{tabular}

Ako se na prethodnu zamisao doda i mogućnost da se frekvencija odabiranja menja oko vrednosti $f_{s}$, umesto diskretne se dobija kontianualna funkcija gustine raspodele. Na slici 3. je ilustrovana takva situacija.
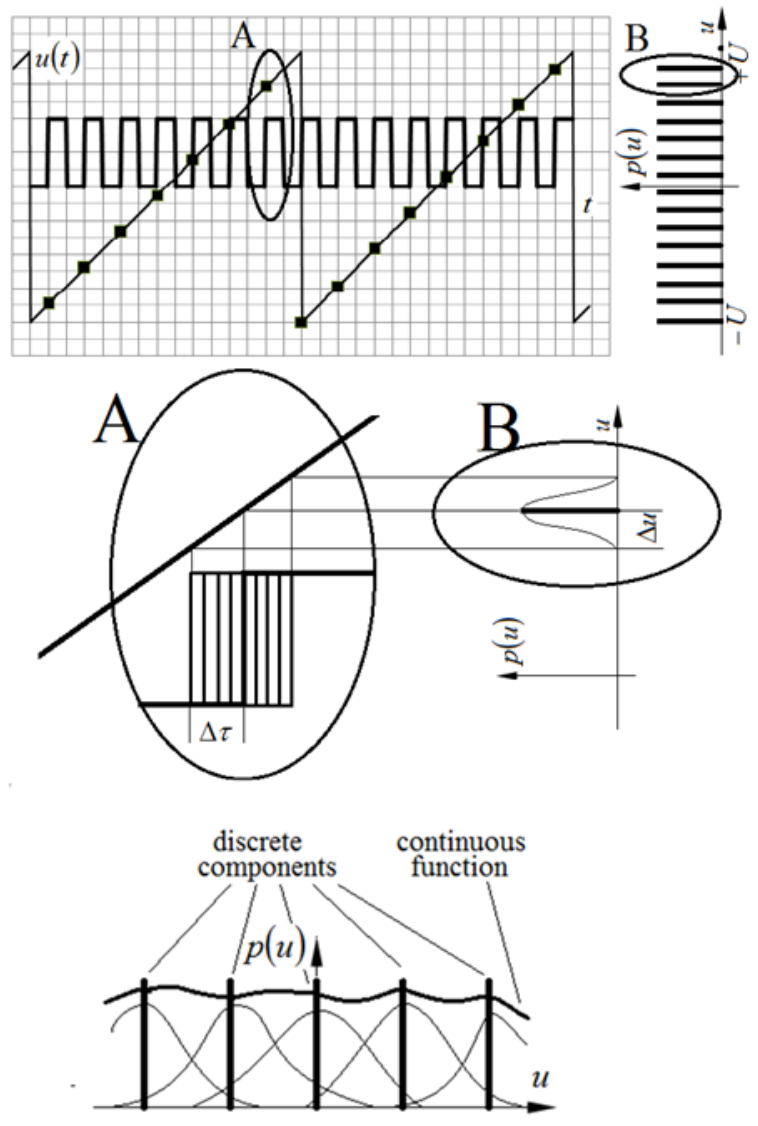

Slika 3. Uticaj ditera na gustinu raspodele
Usled stalnog oscilovanja učestanosti $f_{s}$, dolazi do oscilovanja položaja prednje ivice koja definiše trenutak odabiranja, pa će se odabiranje desiti malo ranije ili malo kasnije. Posledica ovoga je dobijanje nešto manje ili nešto veće vrednosti odbirka u poređenju sa situacijom kada nema oscilovanja. Umesto jedne diskretne vrednosti odbirka, sada dobijamo kontinualan skup mogućih vrednosti. Na osnovu [6] sledi da će suma mnoštva slučajnih promenljivih čije su srednje vrednosti ekvidistantno raspoređene težiti uniformnoj raspodeli (Gaus Step Method).

Osnovna zamisao nove metode za generisanje ditera kontinualnog skupa vrednosti se sastoji od odabiranja jednom u okviru periode testerastog signala. Trenutak odabiranja je određen: a) pseudoslučajnom vrednošću iz LFSR, b) odnosom učestanosti $\frac{f_{s}}{f}$ i c) indeksom modulacije učestanosti $f_{s}$.

\section{SIMULACIONI MODEL}

Simulacioni model je realizovan u $\mathrm{C}++$. Korisnik može zadati parametre koji određuju način odabiranja testerastog napona.

\subsection{Struktura LFSR}

LFSR je definisan:

a) Dužinom šift registra. Predviđeno je da će maksimalna dužina biti 32 bita, tako da se šift registar simulira promenljivom unsigned integer tipa.

b) Pozicijama sa kojih se uzima povratna sprega. U [7] je data tabela sa optimalnim povratnim spregama koje obezbeđuju maksimalno dugačku pseudoslučajnu sekvencu.

c) Vrsta povratne sprege: preko XNOR ili XOR kola.

d) Pozicije sa kojih se uzimaju bitovi i formira vrednost koja definiše trenutak odabiranja u okviru jedne periode testerastog napona. Za $m$ definisanih pozicija, srednja vrednost odnosa učestanosti treba da bude $2^{m}$.

\subsection{Oblik ulaznog napona}

Teorija se bavi testerastim naponom, a u praksi se koristi trougaoni napon, pošto je vrlo teško izvodivo realizovati beskonačno strmu silaznu ivicu testerastog napona. Oba napona imaju uniformnu funkciju gustine raspodele vrednosti, pa se očekuju isti rezultati korišćenjem oba talasna oblika.

\subsection{Način modulacije}

Predviđena su dva načina modulacije učestanosti odabiranja: deterministički i stohastički. Kod determinističkog načina modulacije realizovana je promena učestanosti $f_{s}$ po trougaonoj funkciji. Kod stohastičke modulacije $f_{s}$ je odabrana trougaona funkcija gustine raspodele odstupanja frekvencije $f_{S}$.

\subsection{Odnos učestanosti}

Odnos učestanosti se zadaje u obliku $N, 1,-1,1 \ldots$ pri čemu je $N=2^{m}$ a ostali brojevi predstavljaju koeficijente polinoma $\left(\frac{1}{2}, \frac{1}{4}, \frac{1}{8} \ldots\right)$. Pored celobrojnog odnosa učestanosti, moguće je definisati i necelobrojan odnos učestanosti, takav da ga je moguće lako realizovati hardverom na bazi fazno zaključane petlje i dva delitelja učestanosti [5]. 


\subsection{Indeks modulacije}

Bilo da je odabran deterministički ili stohastički način variranja učestanosti odabiranja, indeks modulacije predstavlja amplitudu promene učestanosti relativno iskazanu u odnosu na učestanost $f_{s}$.

\subsection{Način ispisa u fajl}

Predviđena su dva načina zapisa. U prvom slučaju se u fajl zapisuju realni brojevi kao vrednosti odbiraka. Ovako organizovan fajl je namenjen za statističke testove koji proveravaju uniformnost $\mathrm{i}$ druge stohastičke osobine ditera. Drugi način zapisa je u obliku niza nula i jedinica dobijenih iz binarne reprezentacije odbiraka napona. Ovakav fajl je namenjen za statističke testove koji služe za proveru primenjivosti generatora slučajnih vrednosti $u$ kriptografiji [8].

\section{REALIZACIJA SIMULACIONOG MODELA}

Da bi se zadržala jednostavnost softverskog rešenja i pritom omogućilo da implementacija bude: efikasna, lako nadogradiva i portabilna odabran je $\mathrm{C}++$ programski jezik [9]. Svaka komponenta simulacionog modela je korisniku predstavljena interfejsom (abstraktnom klasom) sa osnovnim funkcionalnostima a implementirana u klasama koje ga nasleđuju. $\mathrm{Na}$ taj način je postignuta modularnost sistema i omogućena jednostavna nadogradnja novim funkcionalnostima.

\subsection{LFRS}

Osnova LFSR je 32bitna varijabla koja u svakom trenutku čuva vrednost registra sa metodama za: šiftovanje, računanje bita pariteta, čitanje izlazne vrednosti. LFSR je još definisan parametrima za: dužinu, inicijalnu vrednost, tip povratne sprege, bitskim maskama za povratnu spregu i izlaznu vrednost registra. Prelazak u naredno stanje se dobija računanjem bita pariteta, šiftovanjem za jedan korak $\mathrm{u}$ desno i setovanjem izračunatog bita na MSB polje.

Korisniku klase su na raspolaganju metode kojima se inicira prelazak u naredno stanje i metode za dobijanje vrednosti od interesa u svakom koraku.

\subsection{Signali}

Naponski i diter signali su predstavljeni klasama koje nasleđuju osnovni interfejs, različit za periodične, stohastičke i druge tipove funkcija. Obavezna je implementacija oblika vremenske funkcije kojom se dobija vrednost signala u zavisnosti od vremena.

\subsection{Odabiranje}

Odabiranje je izvedeno kompozicijom LFSR, naponskog i diter signala. Zasniva se na izračunavanju intervala odabiranja iz odnosa učestanosti. Izlaznim vrednostima iz LFSR se množi interval odabiranja i tako dobija vreme u kome odabiramo vrednost napona.

Različite modulacije $f_{s}$ se dodaju novim nasleđivanjem osnovnog interfejsa i implementacijom stohastičke ili determinističe funkcije modulacije.

\subsection{Konfiguracija $i$ ispis}

Implementacija simulacionog modela sadrži i rutine za ispis vrednosti u fajl, alate za bitsku manipulaciju i sistem za konfiguraciju same simulacije.
Pri pokretanju simulacije, učitava se konfiguracioni tekstualni fajl sa mapiranim imenima i vrednostima parametara (key-value struktura).

Konfiguracijom je omogućeno da se primenom Abstract Factory paterna [10] izabere jedna od postojećih implementacija za svaku komonentu, dužina registra, funkcija pariteta. Takođe je potrebno definisati oblik ispisa (binarni ili decimalni) i broj odbiraka koji će simulacija napraviti.

\section{REZULTATI SIMULACIJA}

$\mathrm{Na}$ slici 4. prikazan je histogram u slučaju testerastog talasnog oblika, bez modulacije učestanosti odabiranja, za tri vrednosti učestanosti odabiranja.

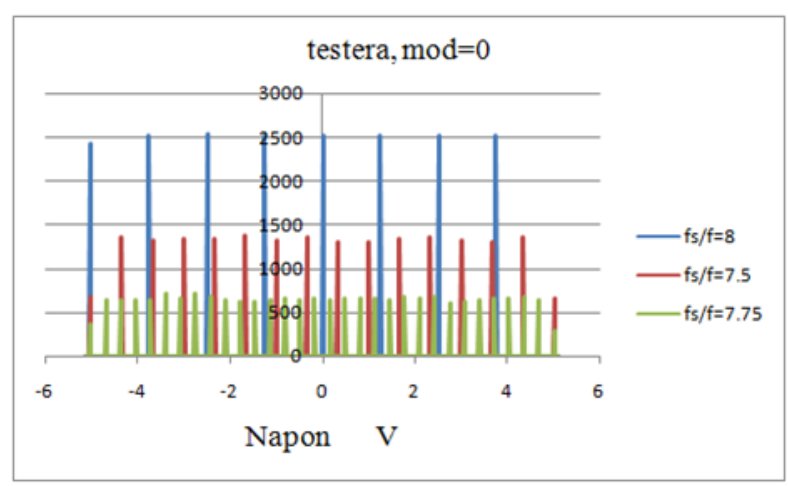

Slika 4. Histogram, bez modulacije učestanosti

Dobijamo diskretan skup vrednosti odbiraka. Broj mogućih vrednosti se ponaša u skladu sa teorijskim predviđanjem datim u Tabeli 1 .

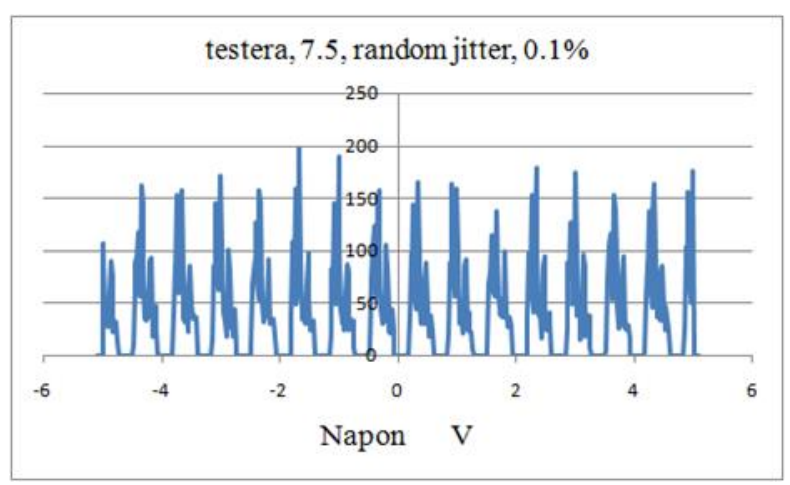

Slika 5. Histogram, stohastička modulacija, 0.1\%

$\mathrm{Na}$ slici 5. je prikazan histogram vrednosti odbiraka pri srednjoj vrednosti odnosa učestanosti 7.5, sa stohastičkom modulacijom učestanosti odabiranja i indeksom modulacije $0.1 \%$. Uočava se opseg vrednosti umesto jedne diskretne vrednosti koja se dobija u slučaju bez modulacije. Opsezi nisu međusobno preklopljeni, i dalje postoje vrednosti koje se nikada ne dešavaju.

Na slici 6. je prikazan histogram vrednosti odbiraka pri srednjoj vrednosti odnosa učestanosti 7.5, sa stohastičkom modulacijom učestanosti odabiranja i indeksom modulacije $0.5 \%$.

Opsezi se sada preklapaju, sve vrednosti iz opsega testerastog napona su moguće, ali nisu sve vrednosti podjednako moguće. 


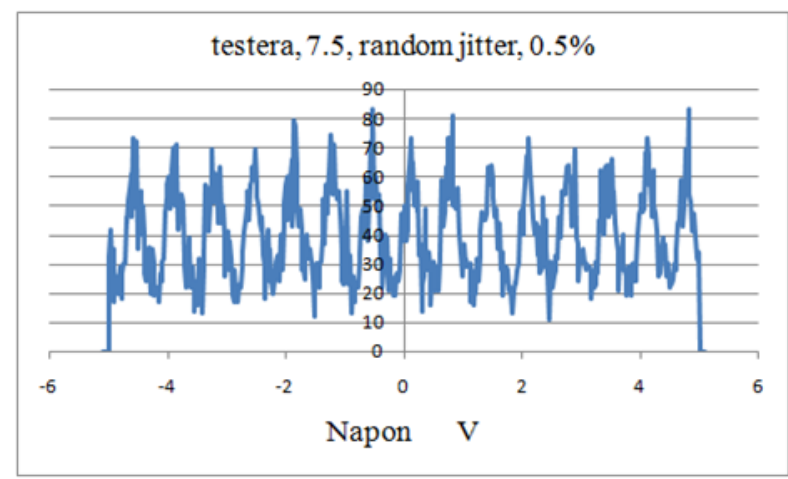

Slika 6. Histogram, stohastičkoa modulacija, 0.5\%

Na slici 7. je prikazan histogram vrednosti odbiraka pri srednjoj vrednosti odnosa učestanosti 7.625, sa stohastičkom modulacijom učestanosti odabiranja i indeksom modulacije $0.5 \%$.

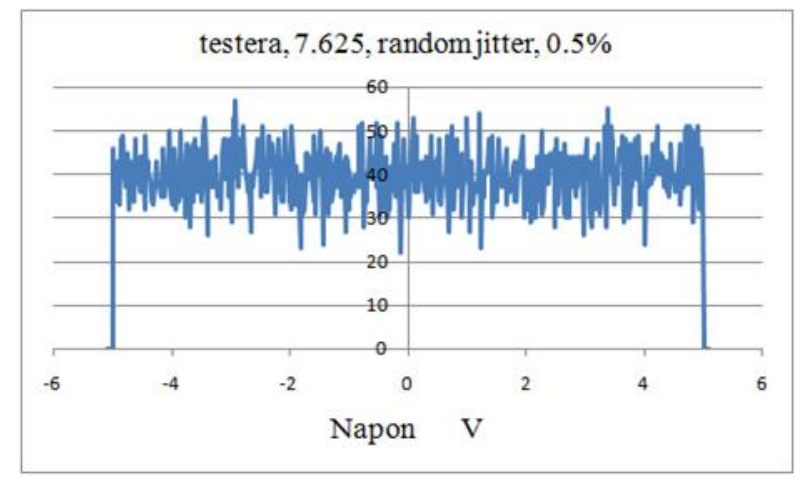

Slika 7. Histogram za odnos učestanosti 7.625

Sada su sve vrednosti iz opsega testerastog napona moguće, ali ovoga puta sa približno jednakim verovatnoćama. Ista zavisnost se vidi na slici 8 , ovaj put nacrtana sa deset puta manje tačaka po horizontalnoj osi.

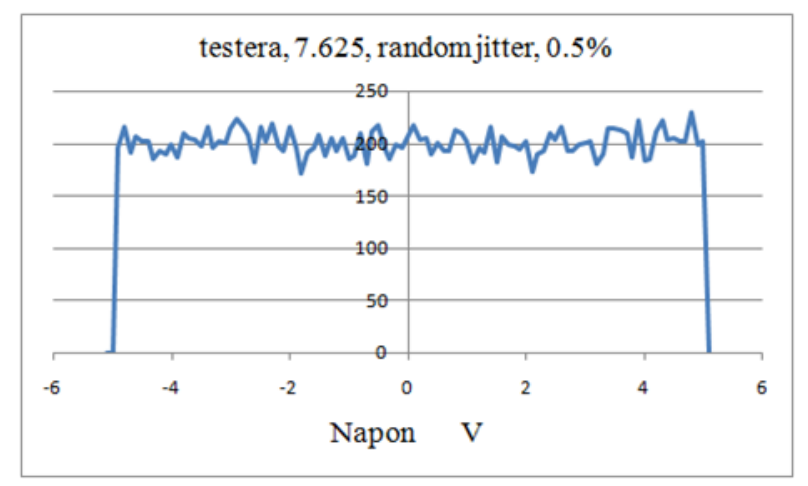

Slika 8. Smanjen broj iscrtanih tačaka na x-osi

\section{ZAKLJUČAK}

Softverskom simulacijom modela su omogućeni neophodni koraci pri projektovanju hardverskog sistema: analiza, optimizacija i predviđanje ponašanja sistema pre stvarne implementacije. Omogućena je dobra polazna osnova za istraživanje predložene metode generisanja šuma.
Dodavanjem vizuelne prezentacije rezultata i podešavanja parametara bi se simulacija približila korisniku. Dodatnim matematičkim uopštavanjem konfiguracije komponenata modela bilo bi moguće dodavati nove implementacije bez softverske intervencije i programerskog predznanja.

\section{LITERATURA}

[1] Vladimir Vujičić, Slobodan Milovančev, Mile Pešaljević, Ivan Župunski, "Low-Frequency Stochastic true RMS Instrument”, IEEE Trans. Instr. Meas., vol 48, pp 467-470, April 1999.

[2] Vladimir Vujičić, "Generalized Low-Frequency Stochastic True RMS Instrument", IEEE Transactions on Instrumentation and Measurement, Vol. 50., No. 5, October 2001.

[3] D. Pejic, V. Vujicic, "Accuracy limit of high precision stochastic watt-hour meter ", Instrumentation and Measurement, IEEE Transactions (Volume: 49, Issue: 3), June 2000, pp. 617-620, doi: 10.1109/19.850404.

[4] Urekar Marjan Gazivoda Nemanja V Pejic Dragan, "The Core for High-Precision Stochastic Smart Grid Meter Based on Low-Resolution Flash ADC", IEEE TRANSACTIONS ON INSTRUMENTATION AND MEASUREMENT, (2019), vol. 68 br. 6, str. $1705-1713$

[5] D. Pejić, N. Gazivoda, B. Ličina, M. Urekar, P. Sovilj, B. Vujičić, "A Proposal of a Novel Method for Generating Discrete Analog Uniform Noise", Advances in Electrical and Computer Engineering, Vol. 18, No. 3, doi:

10.4316/AECE.2018.03009, 2018.

[6] J. Neškudla, J. Vedral, "Digitaly controlled white noise generator", 2006. URL:

http://www.imeko.org/publications/wc-2006/PWC-2006-TC4IWADC-008u.pdf (31.01.2016.)

[7] Donald E. Knuth, "The Art of Computer Programming”, Volume 3, Sorting and Searching.

[8] F. Pareschi, R. Rovatti, G. Setti, "On statistical tests for randomness included in the NIST SP800-22 test suite and based on the binomial distribution", IEEE Transactions on Information Forensics and Security, 7(2), pp.491-505, 2012.

[9] Scott Meyers, "Effective C++", Addison-Wesley Professional; 3 edition (May 22, 2005)

[10] Erich Gamma, Richard Helm, Ralph Johnson, John Vlissides, "Elements of Reusable Object-Oriented Software", Addison-Wesley Professional; 1 edition (October 31, 1994)

\section{Kratka biografija:}

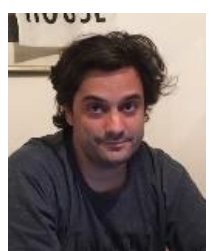

Marko Knežević rođen je u Užicu 1982. god. Radi kao programer u Novom Sadu. Master rad na Fakultetu tehničkih nauka iz oblasti Elektrotehnike i računarstva odbranio je 2019.god. 